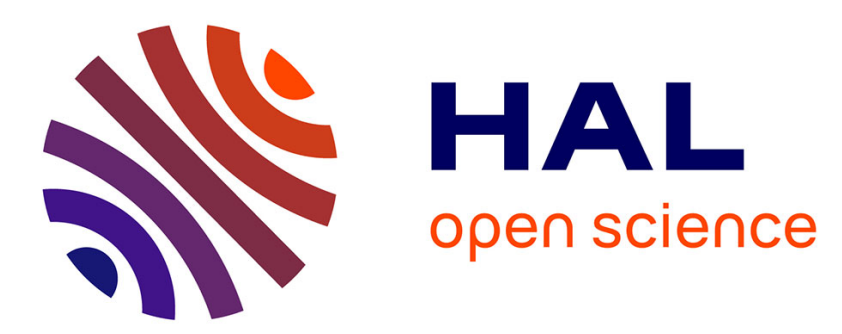

\title{
Low-Income Parents' Values Involving the Use of Technology for Accessing Health Information
}

\author{
David Muñoz, Rosa I. Arriaga
}

\section{To cite this version:}

David Muñoz, Rosa I. Arriaga. Low-Income Parents' Values Involving the Use of Technology for Accessing Health Information. 15th Human-Computer Interaction (INTERACT), Sep 2015, Bamberg, Germany. pp.53-70, 10.1007/978-3-319-22698-9_5 . hal-01609389

\section{HAL Id: hal-01609389 \\ https://hal.inria.fr/hal-01609389}

Submitted on 3 Oct 2017

HAL is a multi-disciplinary open access archive for the deposit and dissemination of scientific research documents, whether they are published or not. The documents may come from teaching and research institutions in France or abroad, or from public or private research centers.
L'archive ouverte pluridisciplinaire HAL, est destinée au dépôt et à la diffusion de documents scientifiques de niveau recherche, publiés ou non, émanant des établissements d'enseignement et de recherche français ou étrangers, des laboratoires publics ou privés. 


\title{
Low-Income Parents' Values Involving the Use of Technology for Accessing Health Information
}

\author{
David Muñoz ${ }^{1}$, Rosa I. Arriaga ${ }^{2}$ \\ ${ }^{1}$ IBM Watson, IBM, Pittsburgh, USA \\ dmunoz@us.ibm. com \\ ${ }^{2}$ School of Interactive Computing, Georgia Institute of Technology, Atlanta, USA \\ arriaga@cc.gatech.edu
}

\begin{abstract}
Technology is increasingly available to end users of low socioeconomic status (SES), yet little is known about how these users' values affect the interfaces they prefer when seeking information related to their child's health. We investigate low-SES parents' preferences when it comes to technology to track and learn about their child's developmental milestones using both qualitative and quantitative analy ses. We follow the methods outlined by Value Sensitive Design (VSD) and found that the three most relevant values for information seeking are Convenience, Learning/Bonding and Trust. We also discuss how these values drive their technology preferences in tracking their child's developmental milestones. We also present a series of design principles for information communication technology for low-SES user groups that were derived directly from our qualitative research with 51 participants. We note that although working in this unique problem space necessitated following an abridged VSD paradigm our results align with the core set of values suggested by VSD.
\end{abstract}

Keywords: value sensitive design; public sector; qualitative methods

\section{Introduction}

With the increasing prevalence of technology, researchers can use digital devices for addressing health-related research questions). Currently, there are over seventeen thousand general health-related mobile apps ${ }^{1}$ [9]. However, there is little regulation of the accuracy of the mobile app's content. As long as a mobile app follows Apple or Google's design guidelines, it can be accepted into the App Store or Google Play Store, respectively [9]. Reliable health information is especially critical when it is related to young children because of their rapid growth. For example, developmental disorders affect 1 in 6 children in the US [4]. Early detection of these disorders is important for many reasons such as earlier intervention and treatment, as well as benefits like improved social skills and cognitive functioning [6,24,28]. There are now many mobile apps to help individuals with autism and their caregivers with various

1 "Mobile apps" will be the term used in the rest of this paper to refer to applications developed for mobile phones (as opposed to desktop or web applications, or "apps") 
daily activities, including reference and messaging systems for social interactions $[3,16]$. However, few programs provide parents with a comprehensive and holistic reference and log for their child's developmental progress [17,19,20]. Currently there are no mobile apps that focus on early tracking of developmental milestones. Children who are diagnosed with autism spectrum disorder (ASD) and other developmental disabilities may be late to show important developmental milestones. Thus, a parent's ability to know if his child is meeting these milestones may have important implications. However, keeping track of a child's developmental progress is made difficult by several factors. First, the quantity of developmental milestones a child should reach at certain ages can be overwhelming. Second, parents may need to reference milestones for older or younger age ranges to ensure the observed behavior is appropriate. Third, the fact that children develop in a unique fashion means that some milestones may be reached in a slightly different order than expected [37]. Due to these and other difficulties, less than half of children with developmental delays, including autism, are diagnosed before Kindergarten, leading to postponed treatment and intervention [35]. In this paper, we address the role technology can play in facilitating parents' ability to track their child's developmental milestones. We focus on families from low socioeconomic status (SES) because research indicates that their children are more likely to suffer the deleterious effects of late referrals and diagnoses of developmental disorders. For example, low-SES African American and Hispanic parents reported developmental concerns about 2 years later on average than Caucasian parents [29]. This in turn leads to the under-diagnosing of African American and Hispanic children with ASD [22]. A later diagnosis is associated with decreasing the impact that comes with receiving early treatment and intervention [10,11,33]. We used a Value Sensitive Design (VSD) methodology [12] to understand the underlying values that low-SES parents hold in terms of learning about their children's health in order to design the most appropriate solution (see section 2 below for more discussion on VSD terminology). To reach low-SES parents of diverse racial backgrounds, we collaborated with the USA's Women, Infants, and Children (WIC) organization that provides nutritional and health services to mothers and children living $180 \%$ below the poverty level [36]. As mentioned earlier it is important to test parents of diverse racial backgrounds because there are different developmental outcomes among these demographics [22, 29]. Additionally, WIC is an appropriate venue to carry out this study because their organizational mission includes the goal of educating parents about their child's development and developmental milestones, meaning that they are considering various approaches for effectively communicating this information. The study goal was to gather insights into technology use and attitudes towards technology that should be considered when developing tools for tracking developmental milestones for low-SES parents. Our work makes three contributions. First is the utilization of the VSD method with low SES parents in an ecologically valid setting, a community clinic. Here we show that the VSD was especially helpful given our collaboration with a client (the WIC) with limited HCI research experience. Second is an understanding of the values that low SES parents' have when tracking their child's milestones and how this relates to their interface preferences for tracking their child's developmental milestones. While there have been other research projects involving health-related information 
seeking [7,39], this work expands the utilization of VSD to health related information seeking on children's development, specifically. Finally, we present a series of design principles for information communication for low-SES user groups that were derived directly from our conceptual and empirical studies.

\section{VSD Framework Overview}

Values are "something that a person or group of people consider as important in life" [12]. Therefore, the goal of the VSD framework is to see which "enduring human values" are shared by users in a specific scenario [12]. Friedman et al [12] provide 13 broad examples of values (e.g., "privacy", "informed consent"), though this list is not meant to be exhaustive and instead is meant to be adapted based on the context of specific research studies. By identifying these values, designers and researchers can consider the full range of user needs. This understanding of values is developed through a cycle of iterative studies as follows [12]:

- Conceptual Study: derives the values based on existent literature, observations and interviews with users, and other qualitative research methods.

- Empirical Study: measures users' responses to a system in terms of the values identified in the conceptual study.

- Technological Study: involves gathering value-related feedback from long-term usage of a system.

Given the lack of VSD-related work in our target user group, we focused our effort on conducting a conceptual and empirical study. This paper outlines the methods and findings from those studies that will help inform a future technological study. Our goal with these two initial studies was to explore low-SES parents' preferences for digital and non-digital systems for tracking children's development, including: mobile apps, websites, text messages, kiosks, and paper materials. We also took the opportunity to learn more about the existing WIC workflow, as well as the following research topics related to WIC clients: general use of technology at home, attitudes towards technology, and experiences tracking children's development.

\section{$3 \quad$ Related Work}

In the United States and other industrialized countries, mobile apps have great potential for promoting information to young mothers since this demographic is likely to own a smartphone. One study found that mothers with children from ages 0-5 in the U.S. used their phones more often than any other adult in the U.S. [6]. Both industry and researchers have bridged the connection between the ubiquitous nature of phones 
and parent's needs. Text4Baby is a text message ${ }^{2}$ service phones that sends factoids about prenatal and infant health. The company's internal research found ge nerally high usage ( $31 \%$ of users responded to a text message). They also noted increased distribution of knowledge (75\% of users reported learning new medical information from the mobile app), and increased awareness of baby-related issues [32]. Other related approaches include a Twitter-based system [31] and a website [23]. Of these systems, @BabySteps is the only one that focuses on developmental milestones while the other two contain limited amounts of information relevant to these milestones.

Low-SES communities may have different preferences and access to technology than those in high-SES communities. Researchers have investigated these differences in needs and preferences through various health-related projects such as research on the communication between providers and low-SES patients with children [18,27], low-SES adults at risk for cardiovascular disease [30], and low-SES AfricanAmerican communities at risk for diabetes [15]. There has also been similar valuerelated work involving other topics concerning marginalized user groups such as the homeless [21] and low-literacy adults [26]. However, there is no previous work investigating values in these low-SES communities involving the use of technology for accessing health information on children's development. WIC has been the site of a number of studies but these have focused on technology preferences for learning about nutritional information. One study compared WIC client $^{3}$ satisfaction when using paper-based materials vs. a kiosk-based interactive program and found $87 \%$ of clients preferred the kiosk over paper-based materials [34]. The second study found 93\% of WIC clients enjoyed using software for learning about nutritional information [5]. Neither study described the technology utilization of their cohorts nor addressed specific questions about values users had involving information seeking behavior.

\section{Descriptive Study: Understanding the WIC Context}

To address our study goals we needed to 1) systematically observe and understand the workflow of the WIC clinics and 2) develop an understanding of concerns parents may have about their child's development by interviewing WIC nutritionists.

\subsection{Descriptive Study Logistics}

Understanding the logistical aspect of the WIC visit would allow us to understand how to contextualize the VSD and allow us to infer how possible milestone tracking systems could fit into this environment. As stated earlier, WIC clients are homogenous with respect to financial income [15] but heterogeneous in other ways, including

2 "Text message" will be used in the rest of this paper to refer to short text-based messages sent electronically between mobile phones. These "text messages" may also be referred to as "short message service" (SMS)

3 "Client" is the WIC's preferred term for parents and children who receive WIC services 
but not limited to race ${ }^{4}$ and access to technology (see section 5.2, "Client Interviews", for more details). The research team's WIC contacts helped coordinate research activity in a single clinic with high racial diversity. To become more familiar with the WIC workflow and to select the most appropriate time to interview clients, the researcher shadowed a client throughout her visit to the clinic. Then, the researcher shadowed a mother and her child as they went through the WIC certification process.

\subsection{Descriptive Study Materials}

The researchers' university's institutional review board (IRB) approved study protocols to ensure the proposed research would uphold the university's requirements for ethical scientific research. Protocols were also approved by the review board of the district where the WIC clinic was located. All clients provided written consent to participate in the interviews. Given that the descriptive study's focus was to observe the current workflow at the clinic without directly speaking with WIC clients, the researchers did not need any materials for the observations. For the nutritionist interviews, 10 questions were asked about the kind of advice WIC clients seek from nutritionists and the resources that nutritionists recommend as references outside the clinic.

\subsection{Descriptive Study Results}

During check-in, a client was randomly chosen by WIC staff and asked about participating in a research study. The first client chosen in this manner agreed to participate. This process took one hour. Based on this shadowing, the research team developed a step-by-step diagram of the certification process and confirmed these steps with the clinic manager, avoiding the need to shadow additional clients. The manager sugges ted interviewing clients after the nutritionist consultation since the wait time for receiving WIC vouchers generally was the longest wait period for clients, lasting between 10-20 minutes. The manager also advised the team that clients usually try to get in and out of the clinic as soon as possible. Given this new constraint, the interview script was reduced from 25 minutes to 10 minutes.

The initial qualitative research conducted to familiarize the researchers with the WIC clinic and workflow provided insights into the values held by the WIC staff. One of WIC's goals is to find ways to provide educational content related to children's development to its various diverse clients regardless of access to technology. More generally, the overall goal of our collaboration with WIC emphasizes the values of universal usability and freedom from bias, as well as the value of human welfare given that the information on children's development involves children's physical and

4 We consulted with the WIC's existing questionnaires to ensure that the terminology we used (e.g., "race") and the options available (e.g., "African American") were consistent with the terminology used in WIC's own questionnaires. After filling out the questionnaire, parents participated in a semi-structured interview focused on the research questions outlined below. We also include race in our study since it is a variable that has been associated with disparities in healthcare in general and child development in particular [22,29]. 
psychological well-being [14]. Trust is also an important value present in the clinic given that clients consult with a health professional (the nutritionist) about their child or children's health. Lastly, given that the interviews were conducted in a cubicle nearby the other nutritionists' offices, away from the noisier public spaces and waiting room, privacy clearly is important to the clinic.

To understand more about the questions clients ask nutritionists, one of the researchers interviewed three of the six nutritionists in the clinic. The nutritionists mentioned that "[clients'] main concern is "is my child physically growing?" All three mentioned that in addition to questions related to height and weight, the next most common set of questions asked involved nutrition (e.g., picky eating). Question s about speaking and crawling were also fairly common. Overall, the questions typically asked involved milestones that are related to the child's physical development. This is a telling finding because many milestones that are critical for diagnosing autism are ones that involve social interactions (e.g., shared attention to an object between the child and caregiver) and cognitive development (ability to engage in pretend play).

\section{Conceptual Study}

The conceptual study consisted of having parents fill out 1) a survey related to their use of technology and 2) an interview about technology utilization, attitudes toward technology and experience tracking their child's development. The goal of this study was to gain qualitative insights about parents' use of technology and their attitudes towards technology in order to inform an analysis of the values parents hold.

\subsection{Conceptual Study Logistics}

Given that WIC clients are a disadvantaged population, the research team did not want to introduce possibilities for coercion or bias when asking clients to join the research study. The research team discussed this concern with the clinic manager, who suggested the WIC nutritionists should approach the client about the optional research study since they are familiar staff members who interact with parents each visit. Additionally, WIC nutritionists usually inform parents of programs or optional research studies they or their children may be eligible for. Careful attention was given to how nutritionists as ked the clients if they wanted to participate. Particular emphas is was placed on making it clear that the research was optional and would not require the client to stay in the clinic longer then necessary. Clients were told that a student researcher was conducting the interview, that the interview topic was "technology usage at home" and that the interview could be done in English or Spanish. 30\% of clients agreed to participate. To minimize disruptions, the interviews took place in the same area where the nutritionist consultation took place. In one corner of this space was a large empty area that accommodated the researcher, the client, and a spouse/partner and/or children, if applicable. Participants were not provided with a stipend.The consent form and questionnaire were available in both English and Spanish. The consent form described that the interviews would be recorded, and the researcher made sure to emphasize this fact by showing the recording device before beginning the interview. 
Participants were reminded that the interview was optional and that they could stop at any time. First, clients each filled out a brief questionnaire on their own asking about demographic information (age, race, etc). Given the lack of similar past research with low-SES parents, the researchers needed to record possible confounding variables, such as differences in race and age. For example, there could be cultural or other differences between parents of different ages, or between parents of different races (e.g., African American and Hispanic parents) that affect their technology usage, and therefore also affect the values they hold in regard to technology. Without recording this information, the researchers would have no way of accounting for this possible confound.

\subsection{Conceptual Study Materials}

The WIC team picked 5 systems to and probe evaluate WIC clients' values with respect to monitoring their child's developmental milestones. These were based on systems WIC currently had available (kiosk, website) as well as feasible future systems for which our research team had an existing prototype (mobile app, text message). A paper booklet was also included for two reasons. First, the WIC currently uses paper materials for distributing information, so feedback on parents' preferences related to paper sources would be valuable. Second, it is possible that low-SES parents may prefer paper materials depending on their values and access to technology. For the second set of questions, clients were presented with images of the five different systems that could be used to access information about their child's developmental milestones. The interviewer provided a one-sentence description of each system and asked to make sure clients understood the systems' functionality. The interviewer clarified that content would be identical in each system. Clients ranked these in terms of personal preference in order from least to most preferred system. Then, clients rated each option on a 5-point Likert scale with 1 corresponding to "not us eful".

\subsection{Survey Results}

Demographic and technology utilization data was collected from 51 participants. The average age was 30 years and the average educational level was 12 years of schooling (high school degree). There were no significant differences in average age, educational level, or number of children ( 2 children) between races. We consulted with the clinic's records and confirmed that the racial diversity of the parents we spoke with was representative of the overall demographics of the clinics' clients (around 50\% African American, 40\% Hispanic, and 10\% Caucasian). 21 of the 51 participants spoke Spanish. Over half of Hispanic clients (12/21) did part of the protocol in Spanish. Participants were told that they should fill out the entire questionnaire if possible but given the sensitive nature of some questions, that they could withhold any answers they did not feel comfortable sharing. All 51 participants responded to 19 of 21 questions on the questionnaire. 15 parents did not answer the question on financial income, and 4 did not answer about their level of education. All 51 participants provided data that helped us understand their use of technology at home. Table 1 shows 
smartphone adoption is wide spread in this demographic (preference for the Android platform). Of the 10 participants that did not have Internet access on a smartphone, 6 of them had it at home. Four clients reported a lack of Internet access on their phone or at home. African Americans, when compared with Hispanics and Caucasians, were more likely to use other technologies such as laptops and tablets. Hispanics had the least overall technology adoption compared to African Americans and Caucasians.

\begin{tabular}{|l|l|l|l|l|}
\hline & Smartphone & Tablet & Laptop & Desktop \\
\hline African American & $21 / 24$ & $16 / 24$ & $18 / 24$ & $7 / 24$ \\
\hline Hispanic & $15 / 21$ & $3 / 21$ & $8 / 21$ & $4 / 21$ \\
\hline Caucasian & $5 / 6$ & $2 / 6$ & $2 / 6$ & $3 / 6$ \\
\hline All Clients & $41 / 51$ & $21 / 51$ & $28 / 51$ & $14 / 51$ \\
\hline
\end{tabular}

Table 1. Technology Use by Racial Group

Due to time limitations, 48/51 participants provided Likert data for their preferences on the 5 systems we presented. There was a statistically significant difference between parents' preferences for technology (Friedman's test value of $\chi^{2}(4)=48.95, p$ $<.001)$. However, preference distribution was wide, showing that there is no "single" system to meet all parents' preferences (Figure 1). A Wilcoxon signed-rank test was used to look at parents' preferences (Table 2). Parents significantly preferred the app and website over the other three systems. The booklet and text were the next most preferred systems, and the kiosk was significantly the least popular choice.

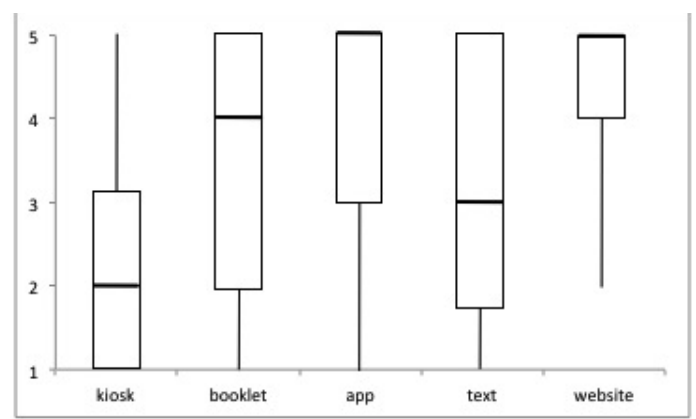

Fig. 1. The $X$-axis shows the 5 interfaces presented to parents. The $Y$-axis shows parents' preferences on a Likert scale for each system

Table 2. P-values from a Wilcoxon signed-rank test (highlighted cells for $\mathrm{p}<.05$ )

\begin{tabular}{|l|l|l|l|l|}
\hline & Website & Booklet & Text & Kiosk \\
\hline App & .222 & .019 & .004 & $<.001$ \\
\hline Website & & $<.001$ & $<.001$ & $<.001$ \\
\hline Booklet & & & .379 & .001 \\
\hline Text & & & & .003 \\
\hline
\end{tabular}




\subsection{Interview Results.}

All 51 participants were interviewed about their values related to technology that could be used to help them track their child's development. The interview data was transcribed and two researchers used three research questions (technology utilization, attitudes toward technology and experience tracking their child's development) to guide the grounded theory (GT) analys is of clients' responses [14]. Values (i.e., categories, defined as conceptual elements that can stand on their own [14]) were identified, as well as related properties (i.e., the conceptual aspects of values [14]). Three core values emerged: 1) convenience, 2) learning/bonding, and 3) trust. These values were used to code individual parents' transcripts. All parents made comments alluding to each value, meaning that these 3 values are held consistently across the parents we spoke with. However, the value in which they placed the most importance (i.e., the value most frequently coded) affected their technology preferences [Table 3]. The following sections describe behaviors associated for each value, each of which was equally distributed across African American, Hispanic and Caucasian clients.

Table 3. Milestone Tracking Interface Preference via Value

\begin{tabular}{|l|l|l|l|}
\hline & $\mathbf{1}^{\text {st }}$ Choice & $\mathbf{2}^{\text {nd }}$ Choice & $\mathbf{3}^{\text {rd }}$ Choice \\
\hline Convenience $\mathbf{( N = 1 6 )}$ & Website & Mobile App & Booklet \\
\hline Learning/Bonding $(\mathbf{N}=\mathbf{1 6})$ & Mobile App & Website & Booklet/Text Message \\
\hline Trust $(\mathbf{N = 1 9 )}$ & Mobile App & Website & Text Message \\
\hline
\end{tabular}

\section{Convenience}

This value involves finding a "convenient" answer to minimize time, energy, and money required. Given WIC clients' busy schedules, responsibilities to their children, and limited time and monetary resources, optimizing their time is crucial for conserving energy throughout the day. The value of convenience is multi-faceted and involves three properties described below.

\section{Digital and Physical Access to Information}

Clients who most valued convenience used their phones often and liked easily accessible systems for finding information, like websites and mobile apps. They liked forum sites like Yahoo! Answers that show feedback from other parents, indicating that these clients may seek validation for their questions. This group disliked the kiosk more than others since they "would have to come back to the WIC clinic and [clients] don't come here very often." These clients also did not like the paper booklet because "it's just something else that might be lost, something I'll have to remember to bring with me everywhere. If I lose it, where would I go for a new copy?"

\section{Cost of Resources}

Some clients said "a [mobile] app and website are free to access, but I have to buy the book." Others thought "the clinic would pay for the kiosk and could be very expen- 
sive." The interviewer did not mention the cost of the systems, so it is interesting to see which resources they inferred were more expensive.

\section{Finding a Quick Answer}

Some clients who valued convenience may do so because they are more or less familiar with certain websites and formats for finding answers to health-related questions (e.g,. WebMD or a Google search). Many of these clients preferred Google, saying "that's the only place I know to go when I have a question." This suggests a potential lack of information literacy in terms of knowing which sources are most reliable since these parents expressed that they viewed the top results as the most reliable. Another client initially provided Google as their preferred resource but then paused for a moment before adding "maybe I should actually talk to a doctor instead of just trusting the Internet." When prompted as to why they might or might not talk to a doctor, however, the client again mentioned, "it can be too much of a hassle."

\section{Learning/Bonding}

These clients emphasized their interest and desire to grow and learn with their child. By learning more about their children, these clients grow a stronger bond between them and their child. These parents described themselves as "naturally inquisitive", regardless of the topic. One particular client mentioned that she was "hands-on. I like to read and learn more, so sites like Google and WebMD let me learn about stuff I didn't know about." While these clients also preferred websites and mobile apps for learning about children's health, their rationale was different than the group that valued Convenience. These clients also sought validation in the form of site reviews and online forum voting/ratings (such as Yahoo! Answers), like the clients who valued convenience. However, whereas the clients who valued convenience liked having a "Top Answer" to quickly scan, this second set of clients appreciated insights from other parents and also sought validation from these parents. This group was more receptive of the kiosk and booklet though they did not restrict themselves to using sources specifically backed up by research. This group particularly liked tips, activities, and other such add-ons. Due to their desire to learn, and be hands-on, these clients enjoyed learning about activities they could do with their child or any feature that suggested similar interactions. While it was heavily emphasized that all the systems would contain the same information, this group preferred the website, mobile app, and booklet. Perhaps these clients perceived those systems as having the clearest affordances and opportunities for providing interaction between client and child.

\section{Trust}

Given WIC clients' financial vulnerability and their children's physical vulnerability, trusting health professionals and related technological systems is crucial. WIC clients seek reassurance that their child is healthy, and this validation can only be obtained when they trust one or both of those sources of information. This value involves two properties: the information itself, and the feeling of reas surance that WIC clients seek through interactions with health professionals and technology. 


\section{Safety and Security of Information}

Clients who most valued trustworthiness of information avoided reference material that was not backed by an expert. This group was the most likely to mention people (such as a doctor or mother) as a resource for learning about children's development. Many of these clients will not accept an answer from anyone other than a doctor or nurse. One client even mentioned that she would "wait until the next doctor's visit" to ask a question instead of finding an answer from another source. Several clients used their clinic hotline to talk with the next available doctor or nurse. One client was a nurse herself and said she "would never use a website, except maybe WebMD since real doctors review that. If I don't know it, I call the doctor right away." Some clients mentioned that the kiosk and text message could lead to losing private information. Several clients said they "would not feel secure using the kiosk because they would have to stand in front of everyone in the clinic. Someone walking by could see my information." For the text message, others mentioned they "would not feel comfortable responding to a system" and preferred recording information on their own.

\section{Reassurance}

Some clients expressed doubt in their ability to accurately record information about children's development, perhaps leading to their preference to rely on health professionals for reassurance. One client mentioned "each child is different, so I don't know what's 'normal' for a specific age. A doctor can help me since he has more experience than me." Similarly, one client said websites were "confusing to navigate." Possibly, these clients prefer speaking to doctors or health professionals because they do not have as much confidence in their use of technology as those clients who value convenience and regularly use their phones, tablets, or other type of computer. While clients in this group tended to review the booklet favorably, one client provided an interesting insight by mentioning "it's hard to update a booklet if there is new information." Perhaps these clients appreciate more trusted sources of content, such as their doctor or WebMD, since they are more aware of recent trends and findings. Indeed, one parent mentioned that "if a text [message] is coming to me from somewhere like webMD, maybe it will include advice, and I trust webMD and would try it." Another client mentioned they liked coming to the WIC since "the nutritionist can see my child in person and give me more specific advice for my child."

\section{Empirical Study}

The empirical study's goal was to get quantitative and qualitative feedback on prototypes to support the qualitative feedback from the conceptual study interviews.

\subsection{Empirical Study Logistics}

After completing the conceptual study (described above), parents proceeded to the Empirical study. The Kano method was used to gather feedback related to the features we implemented. Clients were asked to provide a 1-5 Likert scale rating on how they would feel if the feature 1) was included and 2) was not included [25]. This was done 
for each of the six features [Table 4]. Unlike the common use of Likert scales to express a continuum, the ratings 1-5 are slightly different. " 1 " is "unhappy" and " 5 " is "happy", but a "2" is "I could tolerate this", a "4" is "I would expect this feature to be present/not present", and " 3 " is "neutral". Clients were asked for qualitative explanations for the rating to provide a more complete picture. These comments were recorded to help refine the prototypes. Using established formulas [1] and visualization techniques [28], we identified the level of importance of features (Figure 2).

\subsection{Empirical Study Materials}

Prototypes of the three most preferred technological systems (mobile app, website, text message) were developed to gather clients' feedback. All three systems had the same essential functionality: providing a static list of milestones (e.g., for an 18 month old child, "says and shakes head no"). Additionally, several features directly related to the values identified were added in each of the 3 systems (see Table 3). Given the nature of the different systems, the actual interaction differed slightly, though the ultimate functionality was the same (e.g., for "milestone tracker", the app allowed parents to track all milestones in real time, but in the text message prototype, parents would receive individual text messages for each milestone). This study's goal is to identify features that align with users' values and preferences that could help improve the use of the technology to track developmental milestones in a subsequent technological study. This is important given the difficulty involved in encouraging parents to adopt a new behavior (i.e., tracking developmental milestones). Based on the values identified in the conceptual study, a list of related features was created (described in detail in Table 4). While these features were created to appeal to a specific value, there is of course some overlap. For example, uploading photos could be useful for parents to bond with their children by creating a digital scrapbook to share with friends and family. "Example pictures" could be a convenient and visual way to check if your child has reached certain milestones.

Table 4. Technology Features Related to Values

\begin{tabular}{|l|l|l|}
\hline Value & $\begin{array}{l}\text { Feature } \\
\text { Reminders }\end{array}$ & $\begin{array}{l}\text { Feature Description } \\
\text { Notifications of upcoming milestones a child } \\
\text { should be reaching }\end{array}$ \\
\hline Convenience & $\begin{array}{l}\text { Search } \\
\text { Function }\end{array}$ & $\begin{array}{l}\text { A search engine that returns relevant } \\
\text { milestones based on a term of interest }\end{array}$ \\
\hline $\begin{array}{l}\text { Learning/ } \\
\text { Bonding }\end{array}$ & $\begin{array}{l}\text { Milestone } \\
\text { Tracker }\end{array}$ & $\begin{array}{l}\text { A systemfor logging whether a child has or } \\
\text { has not reached age-specific milestones }\end{array}$ \\
\hline Learning/ & $\begin{array}{l}\text { Suggested } \\
\text { Activities }\end{array}$ & $\begin{array}{l}\text { A list of activities that can help children's } \\
\text { development (e.g., "use simple phrases") }\end{array}$ \\
\hline Trust & $\begin{array}{l}\text { Example } \\
\text { Pictures }\end{array}$ & $\begin{array}{l}\text { An example picture of what milestones look } \\
\text { like (e.g., "plays simple pretend") }\end{array}$ \\
\hline Trust & $\begin{array}{l}\text { Photo } \\
\text { Uploader }\end{array}$ & $\begin{array}{l}\text { For each milestone, uploading a photo of } \\
\text { one's child as a reference }\end{array}$ \\
\hline
\end{tabular}




\subsection{Empirical Study Results}

Time constraints limited the number of clients that completed the Empirical Study $(\mathrm{N}=16)$. Thus, we limit our analyses to group statistics for the six features tested. The most compelling finding is that the two features related to convenience ("reminders" and "search function") would lead to the greatest satisfaction if included and also the greatest dissatisfaction if not included. Features related to trust ("u ploading photos", "example pictures") would not necessarily be "missed" by parents if excluded but would lead to a moderate level of satisfaction if included. The responses for features related to learning and bonding ("milestone tracking", "suggested activities") were similar to those for convenience. "Suggested activities" is the only feature that leads to interaction with the child outside of the client/mobile app interaction, whereas the other features involve an interaction between the client and the mobile app. A technical study using these or other features should note to what extent these different kinds of interactions are seen as useful or not. Given that the empirical study involved a one-time interaction with a mobile app, it may be the case that suggested activities would be more cumbersome to follow in a more realistic long-term deployment.

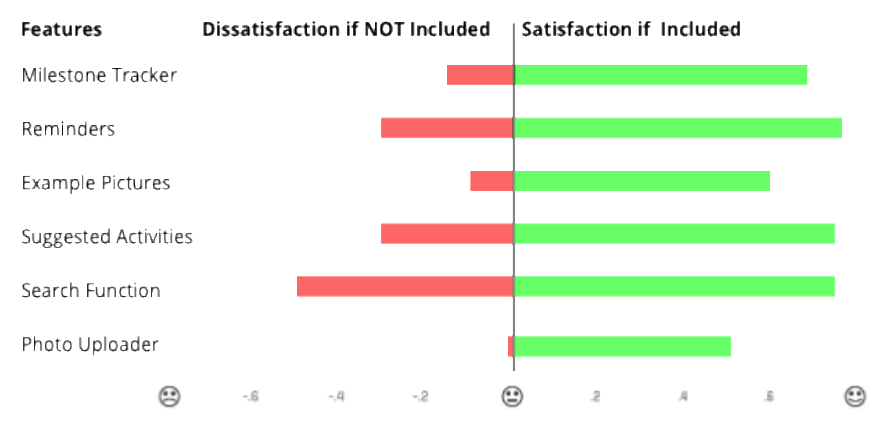

Fig. 2 Feature Preference based on Value $(\mathrm{N}=16)$

\section{Discussion}

Parent's ability to know if his/her child is meeting milestones may have important medical implications since 1) children diagnosed with a variety of developmental disabilities may be late to show important developmental milestones and 2) children from low SES families are more likely to be diagnosed at a later age than their middle SES counterparts, leading to worse long-term outcomes [22,29]. The goal of the present study was to gather insights into technology use and values that low-SES parents have for accessing information about their child's developmental milestones through a variety of interfaces. We did field research in a community clinic to gather ecologically valid information from low-SES Americans. We found that this demographic had high smart phone adoption and some differences among African Americans, Caucasians and Hispanics' utilization of other technology (laptops, desktops, and tablets). However, even with these differences, parents' values and technology preferences 
were consistent. According to our results, three values drove WIC client's technology adoption: 1) convenience, 2) learning/bonding, and 3) trust. We also found that values affected the client's interface preferences.

\subsection{Designing value-sensitive systems for milestone development for low-SES parents}

None of the 51 clients knew what the term "developmental milestone" meant. Upon clarification, only one client mentioned tracking her child's developmental progress through a paper-based calendar system. Some clients mentioned asking their doctor at each visit if their child was developing normally. Based on these findings, it is clear that while clients used technology and other resources from time to time, logging developmental milestones is an unknown concept. Further, data from the nutritionists emphasized that most of these parents conceptualize development as being related to physical growth (e.g., eating certain foods, talking, crawling). However, indicators of developmental disabilities, such as autism, are associated with social milestones that may not be on the parent's radar. This further legitimizes the need for a tracking system that introduces parents to motor, cognitive and social milestones.

We found that WIC clients' attitudes greatly affect their technology utilization preferences. While clients who value trust strongly may avoid sources that aren't necessarily backed by expert sources such as Google and Internet forums, parents who most value convenience may prefer these quick ways to access answers. Additionally, search and forums allow for further exploration of content, an appealing feature for those clients who enjoy learning more about their children's development. In our specific use case, designing a single system that will satisfy the needs of these three client groups may not be possible. While the website and mobile app fared better on average, the features that drive each client group towards using these systems may differ. Additionally, these two systems may have been most popular with clients due to familiarity. Perhaps the website was more popular than the mobile app since there is no popular mobile app for developmental milestone information. Another interesting finding related to WIC clients is that previous research found that they preferred kiosk compared to paper based material to learn about nutritional information [5,34] However, in this study the clients specifically mentioned that the kiosk was not the right interface to track their child's development. They did not feel comfortable recording personal information in a manner that could lead to a breach in privacy (e.g., someone could watch what they entered). This is an important reminder to designers that one interface does not fit all content.

In designing a system to meet our stated goal, we face two possible approaches. The first is to design one interface with multiple views within it to appeal to each of the three values our clients hold. The second consists of designing multiple systems, some of which may appeal to a single value and some of which may appeal to mult iple values. In this second case, the system could potentially be more lightweight and easier to navigate due to the focus on one or two of the values rather than all three. 


\subsection{The value of VSD in the public sector}

VSD provided guidance for assessing values among various stakeholders based on interviews and observations. Table 5 shows values derived from a grounded theory (GT) analysis as well as in terms of VSD's "universal" values [12]. As [2] states, there is a continuing need to "strengthen the voice of the participants in publications." Our GT analysis derived values directly from interviews with end users, preserving their voice and values. We also show that the 3 values we derived (Convenience, Learning/Bonding, Trust) align with 3 of the existing core set of 13 values suggested by VSD (Universal Usability, Autonomy, Privacy/Trust, respectively).

\section{Conclusion}

Tracking a child's developmental milestones is an important step to assuring that children with atypical development get the help they need. Technology, especially mobile devices, offers a powerful design space for assisting parents of various SES levels in logging their child's development. Equally important is that developmental information is available from credible sources (e.g., webMD). Using the VSD framework, we documented the values involving technology use for accessing health information by low-SES parents. Given the lack of VSD work in this user group and context, we focused this study on two of the three kinds of studies that are part of VSD: conceptual and empirical. The present findings will inform the third kind of VSD study, a technological study involving long-term deployment of preferred systems based on parents' values (i.e., mobile app, website). Our study has some limitations that cannot go unstated. As stated in the descriptive study, we only spent 10-15 minutes per participant during regular clinic visits, as suggested by WIC management . The time constraint led to only 16 participants in the empirical study, and perhaps those 16 are different than the other parents who did not complete the empirical study in the same time frame $(\mathrm{N}=35)$. A second is sue was that only $30 \%$ of parents that were asked to participate in the study chose to do so, meaning our findings may not represent the WIC clients that chose not to participate. Also, the participants in this study were more educated (held a high school diploma) than would be expected given their income level. Unfortunately, there are no other studies with WIC clients that can help us clarify these points. Future research may investigate if providing remuneration would affect the sampling rate and in turn the values that parents embrace in regards to technology. As described in the methods section, we randomly asked parents to participate to avoid sampling bias. However, future research should obtain a larger sample in order to better control for possible differences such as these.

In the United States, race is an important factor to consider in studies that address health-related is sues given dis parities between whites, His panics and blacks. As stated in section 5.3, our sample's demographics were consistent across race and comparable to the clinic's overall demographic distribution. We note that our study took place in one urban clinic, so our findings may not apply across all WIC clinics. For example parents we spoke with had a high usage of technology and African American parents owned more digital devices than either Caucasian or Hispanic parents (Table 1). Fu- 
ture research should study rural areas' technology adoption and values. However, one of our WIC advisors, who has traveled to over $95 \%$ of the 200 clinics in the state, mentioned that our findings aligned with his observations of technology use by WIC clients. There is also evidence that the consumer purchasing trends we observed are generalizable (such as the shift towards mobile device ownership). Through our research, we show that developmental milestones and milestone logging are unfamiliar concepts to WIC clients, underscoring why this demographic is at risk for under or delayed diagnosis of developmental disorders. Our research suggests that technology usage in low-income families does not differ drastically from higher-SES parents. Given these two facts, we argue that the values identified as important to this lowSES cohort and their possible effects on technology usage preference will prove us eful to HCI, clinical, and government researchers in their design goals. We expect that knowing low-SES parents' values will help maximize adoption of systems that facilitate tracking children's developmental milestones.

\section{Acknowledgments}

We thank Todd Stormant and Gregory Abowd for their advice on the project, Rushil Khurana and Naveena Karusala for help with interview transcription and analysis, and Barbara Stahnke and Marsha Canning for facilitating our research at WIC. This work was supported by NSF Award No. 1029679 and an NSF Graduate Research Fellowship under Grant No. DGE-1148903. This publication was also supported by the Disability Research and Dissemination Center (DRDC) through its Cooperative Agreement Number 5U01DD001007 from the Centers for Disease Control (CDC) and Prevention. Its contents are solely the responsibility of the authors and do not necessarily represent the official views of the DRDC or the CDC.

\section{References}

1. Berger, C., Blauth, R., Boger, D., Bolster, C., Burchill, G., DuMouchel, W., \& Walden, D.: Kano's methods for understanding customer-defined quality. Center for Quality Management Journal, 2(4), pp. 3-35 (1993)

2. Borning, A., \& Muller, M.: Next steps for value sensitive design. CHI '12 Conference Proceedings, ACM Press, pp. 1125-113 (2012)

3. Boujarwah, F. A., Hong, H., Arriaga, R. I., Abowd, G. D., \& Isbell, J.: Training social problem skills in adolescents with high-functioning autism. In Proceedings of PervasiveHealth, ACM Press, (2010).

4. Boyle, C. A., Boulet, S., Schieve, L. A., Cohen, R. A., Blumberg, S. J., Yeargin-Allsopp, M., ... \& Kogan, M. D.: Trends in the prevalence of developmental disabilities in US children, 1997-2008. Pediatrics (2011)

5. Carroll, J. M., Stein, C., Byron, M., \& Dutram, K.: Using interactive multimedia to deliver nutrition education to Maine WIC clients. Journal of Nutrition Education, 28(1), pp. 19-25 (1996) 
6. Dawson, G., Jones, E. J., Merkle, K., Venema, K., Lowy, R., Faja, S., \& Webb, S. J.: Early behavioral intervention is associated with normalized brain activity in young children with autism. Journal of the American Academy of Child \& Adolescent Psychiatry, 51(11), pp. 1150-1159 (2012)

7. Denning, T., Borning, A., Friedman, B., Gill, B. T., Kohno, T., \& Maisel, W. H.: Patients, pacemakers, and implantable defibrillators: Human values and security for wireless implantable medical devices. CHI'10 Conference Proceedings, ACM Press, pp. 917-926 (2010)

8. Draper, V.: Mobile moms, mobile first. http://advertising.aol.com/blog/mobile-momsmobile-first (2013)

9. Dufau, S., Duñabeitia, J. A., Moret-Tatay, C., McGonigal, A., Peeters, D., Alario, F. X., \& Grainger, J.: Smart phone,smart science: how the use of smartphones can revolutionize research in cognitive science. PloS one,6(9), e24974 (2011)

10. Durkin, M. S., Maenner, M. J., Meaney, F. J., Levy, S. E., DiGuiseppi, C., Nicholas, J. S., $\&$ Schieve, L. A.: Socioeconomic inequality in the prevalence of autism spectrum disorder: evidence from a US cross-sectional study. PLoS One, 5(7), e11551 (2010)

11. Fountain, C., King, M.D., \& Bearman, P.S.: Age of diagnosis for autism: Individual and community factors across 10 birth cohorts. Journal of Epidemiology \& Community Health, 65(6), pp. 503-510 (2011)

12. Friedman, B., Kahn Jr, P. H., Borning, A., \& Huldtgren, A.: Value sensitive design and information systems. In Early engagement and new technologies: Opening up the laboratory. Springer Netherlands, pp.55-95 (2013)

13. Georgia Department of Health. Eligibility Income Guidelines. http://dph.georgia.gov/eligibility-income-guidelines (2012)

14. Glaser, B. G., \& Strauss, A. L.: Awareness of dy ing. Transaction Publishers (1966)

15. Grimes, A., and Grinter, R. E.: Designing persuasion: Health technology for low-income African American communities. Persuasive Technology, Springer Press, pp. 24-35 (2007)

16. Hong, H., Kim, J. G., Abowd, G. D., \& Arriaga, R. I.: Designing a social network to support the independence of young adults with autism. In Proc. CSCW 2012, ACM Press, pp. 627-636 (2012)

17. Janssen, A. P., Tardif, R. R., Landry, S. R., \& Warner, J. E.: "Why tell me now?" the public and healthcare providers weigh in on pandemic influenza messages. Journal of Public Health Management and Practice, 12(4), pp. 388-394 (2006)

18. Jeong, H. Y., Hayes, G. R., Yun, T. J., Sung, J. Y., Abowd, G. D., \& Arriaga, R. I.: Act collectively: opportunities for technologies to support low-income children with asthma. In Proceedings of the 25th BCS Conference on Human-Computer Interaction, pp. 413-420, British Computer Society (2011)

19. Kientz, J. A., Arriaga, R. I., Chetty, M., Hayes, G. R., Richardson, J., Patel, S. N., \& Abowd, G. D.: Grow and know: understanding record-keeping needs for tracking the development of young children. CHI '07 Conference Proceedings, ACM Press, (2007), pp. 1351-1360 (2007)

20. Kientz, J. A., Arriaga, R. I., \& Abowd, G. D.: Baby steps: evaluation of a system to support record-keeping for parents of young children. CHI '09 Conference Proceedings, ACM Press, pp. 1713-1722 (2009)

21. Le Dantec, C. A., \& Edwards, W. K.: Designs on dignity: perceptions of technology among the homeless. CHI '08 Conference Proceedings, ACM Press, pp. 627-636 (2008)

22. Liptak, G.S., Benzoni, L.B., Mruzek, D.W., Nolan, K.W., Thingvoll, M.A., Wade, C.M., \& Fryer, G.: Disparities in diagnosis and access to health services for children with autism: 
Data from the National Survey of Children's Health. Journal of Developmental \& Behavioral Pediatrics, 29(3), pp. 152-160 (2008)

23. Liu, L. S., Hirano, S. H., Tentori, M., Cheng, K. G., George, S., Park, S. Y., \& Hayes, G. R.: Improving communication and social support for caregivers of high-risk infants through mobile technologies. CHI '11 Conference Proceedings, ACM Press, pp. 475-484 (2011)

24. Lovaas, O.I.: Behavioral treatment and normal educational and intellectual functioning in young autistic children. Journal of Consulting Clinical Psychology, 55(1), pp. 3-9 (1987)

25. Moorman, J.: Leveraging the Kano model for optimal results. UX Magazine. http://uxmag.com/articles/leveraging-the-kano-model-for-optimal-results (2012)

26. Munteanu, C., Molyneaux, H., Maitland, J., McDonald, D., Leung, R., Fournier, H., \& Lumsden, J.: Hidden in plain sight: low-literacy adults in a developed country overcoming social and educational challenges through mobile learning support tools. Personal and Ubiquitous Computing, pp. 1-15 (2013)

27. Ngo-Metzger, Q., Hay es, G.R., Chen, Y., Cygan, R., Garfield, C.E.: Improving Communication Between Patients and Providers Using Health Information Technology and Other Quality Improvement Strategies: Focus on Low-Income Children. Medical Care Research and Review, pp. 67 (2010)

28. Perry, A., Cummings, A., Dunn Geir, J., Freeman, N.L., Hughs, S., LaRose, L., et al.: Effectiveness of intensive behavioral intervention in a large, community-based program. Research in Autism Spectrum Disorders, pp. 621-642 (2008).

29. Rosenberg, R.E., Landa, R., Law, J.K., Stuart, E.A., \& Law, P.A.: Factors affecting age at initial autism spectrum disorder diagnosis in a national survey. Autism Research and Treatment (2011)

30. Siek, K. A., LaMarche, J. S., \& Maitland, J.: Bridging the information gap: collaborative technology design with low-income at-risk families to engender healthy behaviors. In Proc. OZCHI '09, ACM Press, pp. 89-96 (2009)

31. Suh, H., Porter, J. R., Hiniker, A., \& Kientz, J. A.: @ Baby Steps: design and evaluation of a system for using twitter for tracking children's developmental milestones. CHI '14 Conference Proceedings, ACM Press, pp. 2279-2288 (2014)

32. Text4baby.: Text4baby research and evaluation. https://text4baby.org/index.php/about/data-and-evaluation (2012)

33. Thomas, P., Zahorodny, W., Peng, B., Kim, S., Jani, N., Halperin, W., \& Brimacombe, M.: The association of autism diagnosis with socioeconomic status. Autism, 16(2), pp. 201213. (2012)

34. Trepka, M. J., Newman, F. L., Huffman, F. G., \& Dixon, Z.: Food safety education using an interactive multimedia kiosk in a WIC setting: correlates of client satisfaction and practical issues. Journal of nutrition education and behavior, 42(3), pp. 202-207 (2010)

35. U.S. Department of Education.: Part C Child Count,1997-2006. http://www.ideadata.org/PartCChildCount.asp

36. U.S. Department of Agriculture.: About WIC's Mission. http://www.fns.usda.gov/wic/about-wic-wics-mission (2013)

37. Volkmar, F. R., Paul, R., Klin, A., \& Cohen, D. J.: Handbook of Autism and Pervasive Developmental Disorders, Diagnosis, Development, Neurobiology, and Behavior. John Wiley \& Sons (2005)

38. Warren, Z., \& Stone, W. L.: Why Is Early Intervention Important in ASC? Autism Spectrum Conditions: FAQs on Autism, Asperger Syndrome, and Atypical Autism Answered by International Experts, pp.167 (2011). 